\title{
IMPLEMENTATION OF SMART MONITORING SYSTEM WITH FALL DECTECTOR FOR ELDERLY USING IOT TECHNOLOGY
}

\section{Norharyati Harum, Zaheera Zainal Abidin, Wahidah Md Shah, Aslinda Hassan}

Department of Computer System and Communication, Faculty of Communication and Information Technology Universiti Teknikal Malaysia Melaka, Hang Tuah Jaya, 76100 Durian Tunggal, Melaka, Malaysia, norharyati@utem.edu.my, zaheera@utem.edu.my,wahidah@utem.edu.my, aslinda@utem.edu.my,www.utem.edu.my

Paper history:

Received 4 October 2018

Received in revised form 26 November 2018

Accepted 28 November 2018

Available online 31 December 2018
Keywords:

Internet of Thing;

Fall Detector;

Raspberry Pi;

Smart Monitoring;

Smart Home;

Image Processing.

\begin{abstract}
Current global statistics shows that increasing number of elderly people live alone. Considering this unavoidable situation, a smart IoT system that can ease young family members to monitor their elderly family member from anywhere has been proposed. In this paper, the system uses a low-cost single board computer, named Raspberry $\mathrm{Pi}$, with embedded webcam to perform 24 hours monitoring is demonstrated. A fall incident can be detected by a captured video that will be processed using an image processing technique. This fall detection is done by several basic activities; separating moving objects from the background, calculating the parameters for these areas and finally, fall detection itself. The fall detector is essential for elderly person monitoring since most of them suffer from chronic diseases and thus need more attention from their young family members. The system can also send notification to the user using social media application when detecting fall incidents in the monitoring area. Video captured by the system will be stored in cloud server, so that it can be used for any incident investigation in the future. By using the system, incidents such as death of elderly family members can be avoided by notifying fall incidents to family members that might be away from home.
\end{abstract}

Copyright (C) Research Institute for Intelligent Computer Systems, 2018. All rights reserved.

\section{INTRODUCTION}

The world's population is ageing at a faster rate than much may have realized. According to [1], nearly $29 \%$ of the 46 million community-dwelling elderly live alone. About half of the communitydwelling elderly people ( $\geq 85$ year) live alone. This is also the situation in Malaysia. According to [2], almost $30 \%$ of the elderly either live alone or with their elderly spouse (compared to $14.7 \%$ in 2004). They are experiencing the Empty Nest Syndrome, with their adult children having left home because of marriage, employment or migration. The remaining $70.1 \%$ of the elderly live with their children or in retirement and care homes. Among 70\% that live with their children, most of them are still left alone during daytime, as their children need to head out for work. Some elderly people live with married children and thus maybe accompanied by their children-in-law. However, it has been reported that female labour participation rate (FLPR) climbed to
$54.1 \%$ in 2015 from $46.8 \%$ in 2010 [3]. This number is predicted to increase due to high cost of living that requires both husband and wife to head out for work. Thus, it is essential to have a system that can help the children to monitor the elderly from anywhere.

On the other hand, Internet-of-Things (IoT) has been referred to as an important keyword in shaping the future to support human life. It is because of its capability to ensure connectivity between people and their machines to support data reachability, so that the data which is automatically collected by devices/machines; can be reached by people from anywhere using an existing Internet service, such as cloud. The definition of IoT is the network of physical objects that contains embedded technology to communicate and sense or interact with their external states or environment [4]. IoT refers to millions of devices that are connected to the Internet, sharing and collecting data. The input device and the single board computer will be integrated together to create the IoT device. Among the sensors that are 
well used in IoT applications are the following ones: the PIR sensor, ultrasonic sensor, soil moisture sensor and many others. Besides sensors, other input devices such as a camera can also be used in IoT applications. Cameras can collect visual data used in any IoT application such as surveillance systems and detection systems [4-6]. Once the data from IoT device is collected, it will be sent through IoT network connectivity such as WiFi and LTE to the user.
Many researchers have tried to use IoT technology in helping elderly monitoring from the outside. Most of the works implement fall detector function as the elderly are exposed to falls due to health conditions [4-6]. As shown in Table 1, most of the published works require complicating and expensive devices. Furthermore, most of the works do not provide complete solutions, which have been developed by using IoT technology.

Table 1 - Comparison between previous projects with proposed system

\begin{tabular}{|c|l|c|c|c|c|c|c|}
\hline $\begin{array}{c}\text { Previous } \\
\text { Work }\end{array}$ & \multicolumn{1}{|c|}{ Description } & $\begin{array}{c}\text { Fall } \\
\text { detection }\end{array}$ & Low Cost & $\begin{array}{c}\text { Data } \\
\text { Storage/B } \\
\text { ackup }\end{array}$ & $\begin{array}{c}\text { Group } \\
\text { Monito- } \\
\text { ring }\end{array}$ & $\begin{array}{c}\text { Remote } \\
\text { Access }\end{array}$ & $\begin{array}{c}\text { Notifica- } \\
\text { tion }\end{array}$ \\
\hline$[4]$ & $\begin{array}{l}\text { The system needs sensorTag to } \\
\text { detect falls. WiFi and Bluetooth } \\
\text { and 3G/4G are required to enable } \\
\text { the whole system. }\end{array}$ & $\sqrt{ }$ & $\mathrm{X}$ & $\sqrt{ }$ & $\sqrt{ }$ & $\mathrm{X}$ & $\mathrm{X}$ \\
\hline$[5]$ & $\begin{array}{l}\text { The system needs a heartbeat } \\
\text { sensor to detect falls. It requires an } \\
\text { expensive device (ARM COTEX). }\end{array}$ & $\sqrt{ }$ & $\mathrm{X}$ & $\mathrm{X}$ & $\mathrm{X}$ & $\mathrm{X}$ & $\mathrm{X}$ \\
\hline$[6]$ & $\begin{array}{l}\text { The system uses a Microsoft } \\
\text { Kinect for detection. GSM is } \\
\text { required for notification via SMS. }\end{array}$ & $\sqrt{ }$ & $\mathrm{X}$ & $\mathrm{X}$ & $\mathrm{X}$ & $\mathrm{X}$ \\
\hline Proposed & $\begin{array}{l}\text { The system uses cameras to detect } \\
\text { falls. It requires Internet } \\
\text { connectivity (WiFi/4G GSM) to } \\
\text { enable data transmission from the } \\
\text { device to both the user and server. }\end{array}$ & $\sqrt{ }$ & $\sqrt{ }$ & $\sqrt{ }$ & $\sqrt{ }$ \\
\hline
\end{tabular}

In this paper, a monitoring device that can monitor the elderly from any location has been developed with fall detection function. Fall incidents are notified to the family members by notification through social media application. Besides, the family members can also monitor their elderly parents from any location for 24 hours as long as they are connected to the Internet. The monitoring view is recorded and saved in cloud, so that it can be used in the event of forensics as the data is safely stored in a different location.

\section{METHODOLOGY AND SYSTEM DESIGN}

Rapid Application Development model is applied to develop the system as shown in Figure 1. The development process goes through the requirements planning phase, user design phase, construction phase and cutover phase.

I. Requirements Planning Phase - In this phase, problems that occur among elderly people and young people who need to leave their elderly family members alone at home due to unavoidable reasons such as working, to determine adequate solution/modules that might help them in ensuring the safety of their elderly family are analyzed. The hardware and software required for the development are also identified in this phase.

II. User Design Phase - In this phase, the monitoring system is designed based on the information required and solution determined in the previous stage.

III. Construction Phase - In this phase, the system based on design in the user design phase is developed. Early tests to ensure functionality of the system have been done. Details of this phase will be discussed in Section 4.

IV. Cutover Phase - In this phase, the functionality of the system is improved based on testing in the previous stage. The overall tests for the developed system are then finalized. Details of this phase will be discussed in Section 4. 


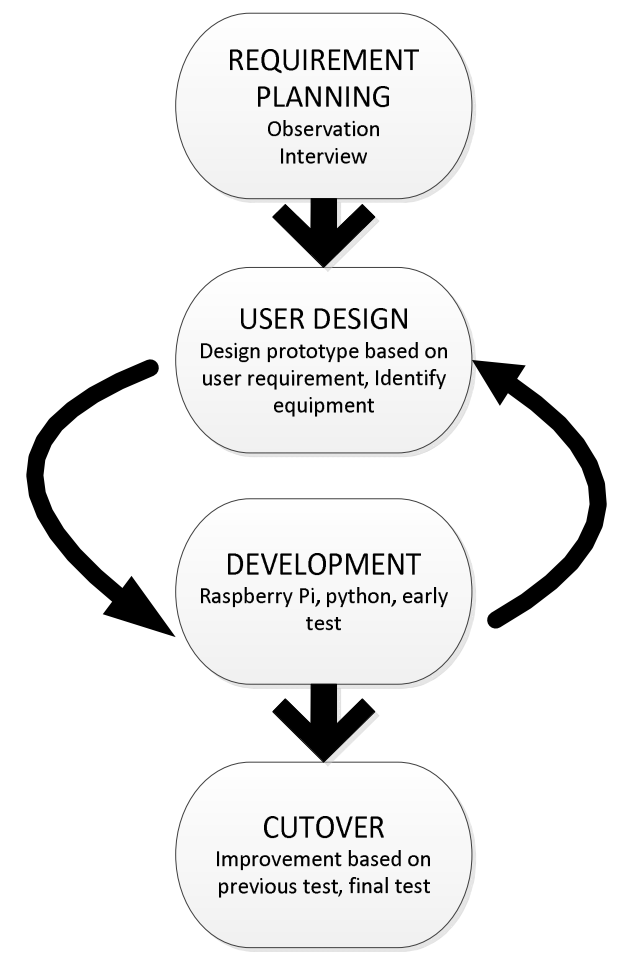

Figure 1 - Rapid Application Development Phase

Figs. 2 and 3 show both the design and flowchart of the developed system.

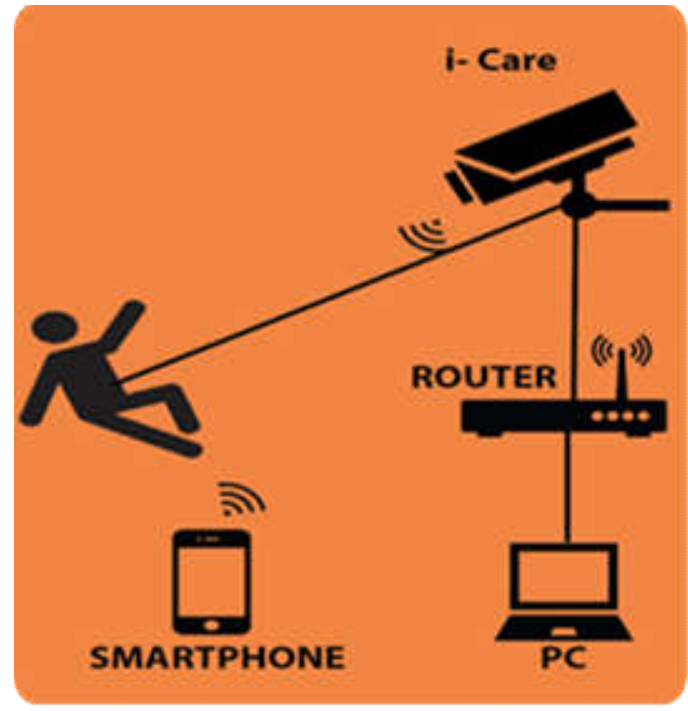

Figure 2 - Design of the proposed system

The system uses Raspberry Pi, camera, router, smartphone and PC. A camera is integrated with a single board computer, Raspberry $\mathrm{Pi}$, to enable 24 hours monitoring and detect falls using the image processing technique. Fall detection process is done in two steps; motion detection and fall detection. The motion detection is done by comparing two consecutive frames of a captured picture using Background Subtraction Method as shown in Fig. 4. In this method, the moving object is separated from the background. The motion can be detected by the difference of image intensity between two consecutive frames. The image subtraction can be represented as:

$$
\Delta I(i, j)=I \text { Current }(i, j)-\operatorname{IPrevious}(i, j)
$$

where $\Delta I(i, j)$ is the difference in image intensity between two consecutive frames; ICurrent $(i, j)$ and IPrevious $(i, j)$ represent image intensities for current and previous frames or background and previous frames or background frame respectively.

On the other hand, fall detection algorithm consists of three steps as mentioned in [7]; movement coefficient analysis, shape analysis, and the last step of the algorithm is used to check whether the person remains motionless on the floor for a few seconds after falling.

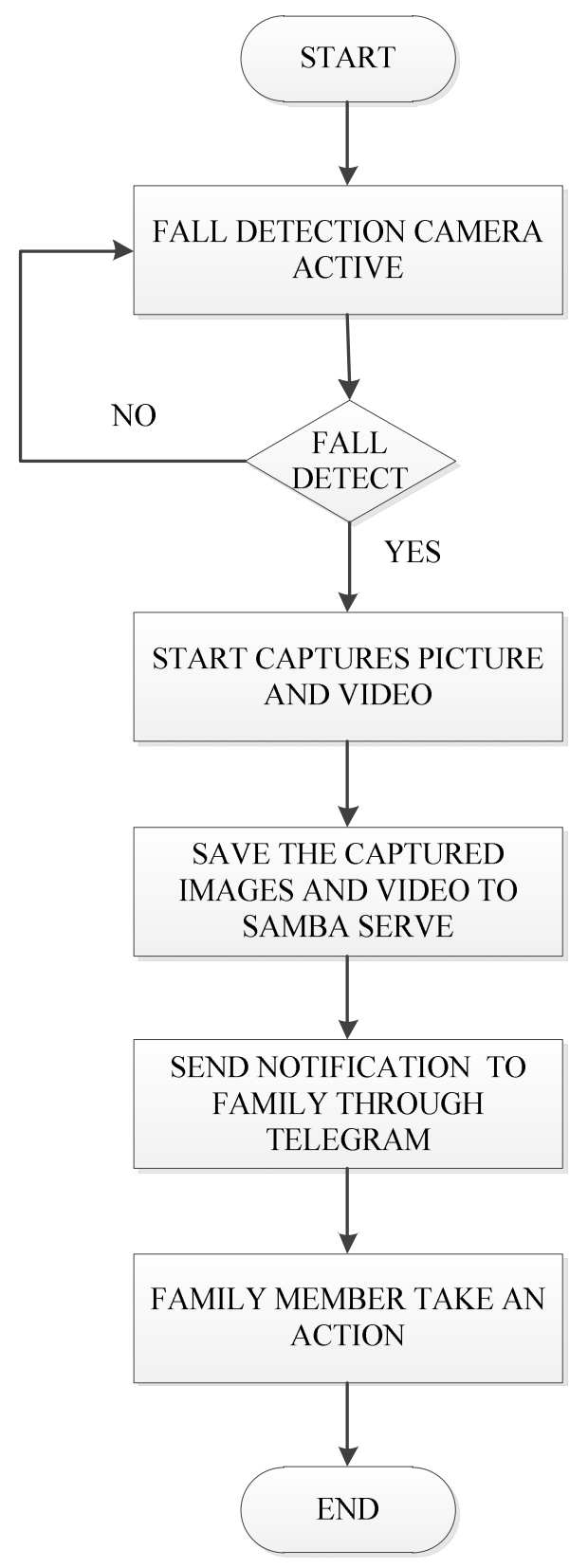

Figure 3 - Flow chart of the proposed system 


\section{IMPLEMENTATION AND TESTING}

Our proposed smart monitoring system for elderly is developed with the embedded function summarized in Table 2. The system consists of 2 IoT devices; Raspberry Pi and Smartphone.

\section{Table 2 - Embedded Function}

\begin{tabular}{|l|l|}
\hline \multicolumn{2}{|c|}{ Smart Fall Detector } \\
\hline Raspberry Pi & Smartphone \\
\hline - Detect motion using Pi & $\begin{array}{l}\text { • Remotely control } \\
\text { the security camera }\end{array}$ \\
Camera Capture picture and & \multicolumn{2}{|c|}{ using Telegram } \\
video using Pi Camera & Enable private \\
when detecting any fall & group access to the \\
- Save the captured & security camera \\
picture and video to & using Telegram \\
server to avoid storage & \\
- Send the captured \\
image and video to \\
user through Telegram
\end{tabular}

Four (4) types of testing have been performed to ensure prototype functionality, which are the movement detection test, fall detection test, notification test, and server test. The testing process is summarized in Table 3.

Figures 5-8 show testing results of the developed system. Colors in the figure show the detected area as mentioned in Table 2. Figure 5 and 6 show the camera detecting movement while Figure 7 shows camera detecting fall. The fall is detected on the basis of object coordination compared with previous captured frame. Also, the fall is detected when there is no movement within certain time of the captured frame.
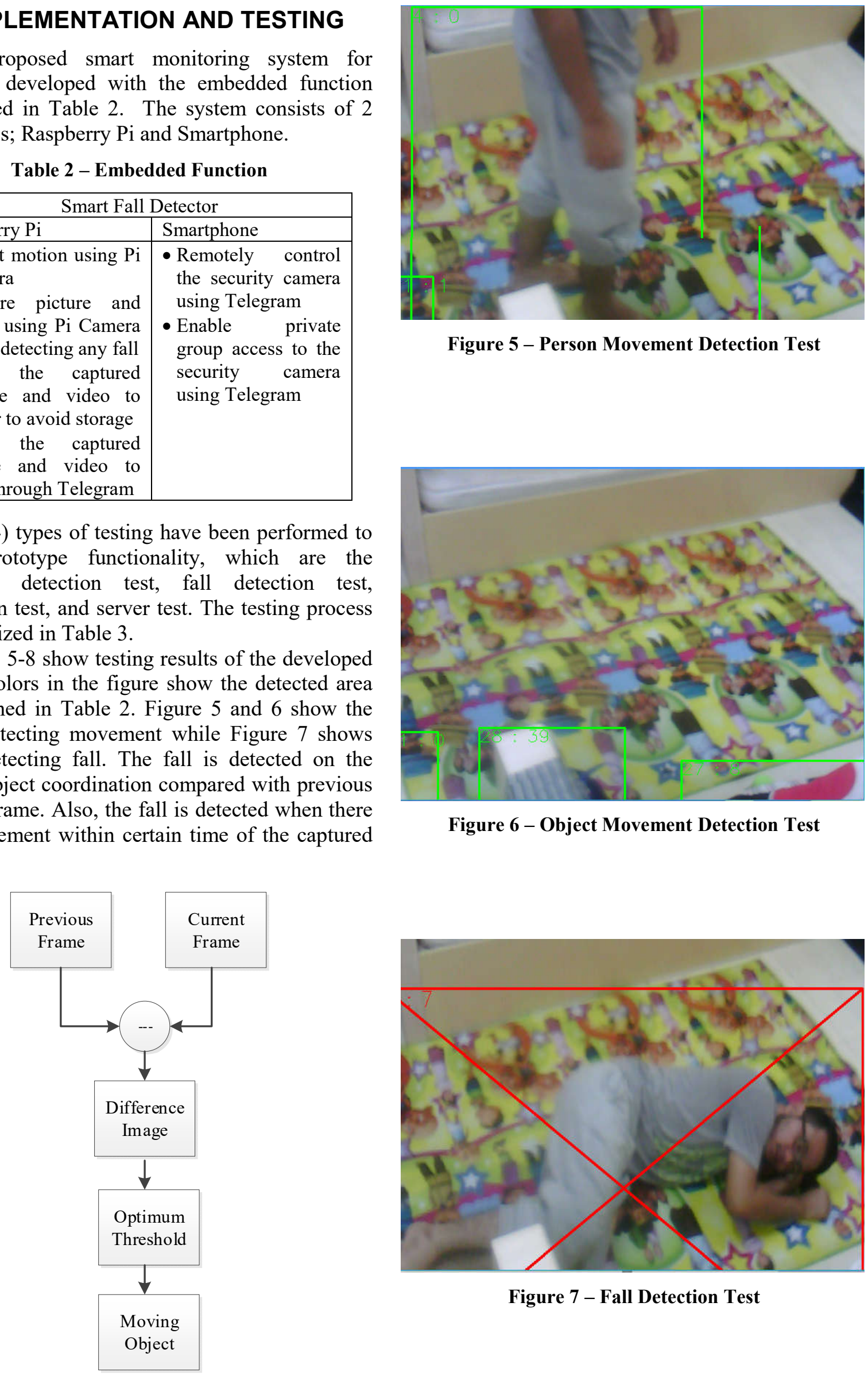

Figure 5 - Person Movement Detection Test

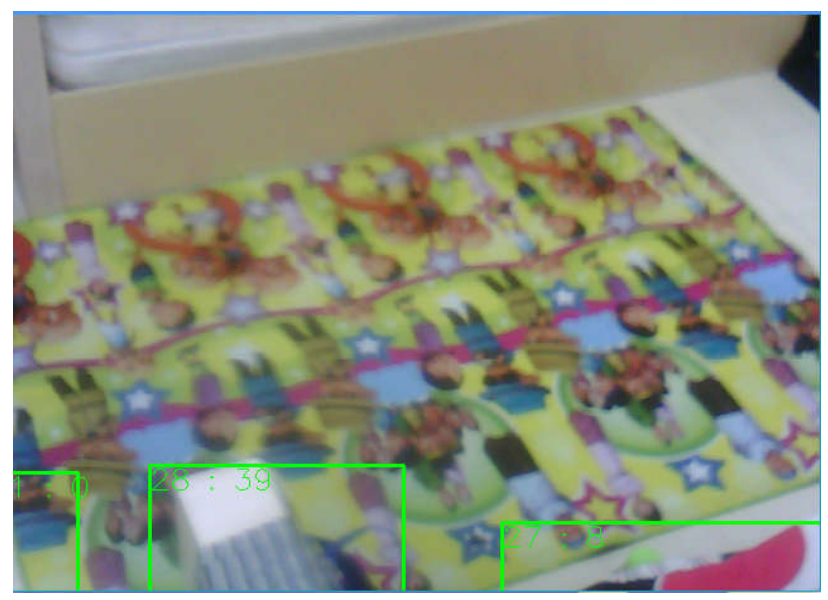

Figure 6 - Object Movement Detection Test

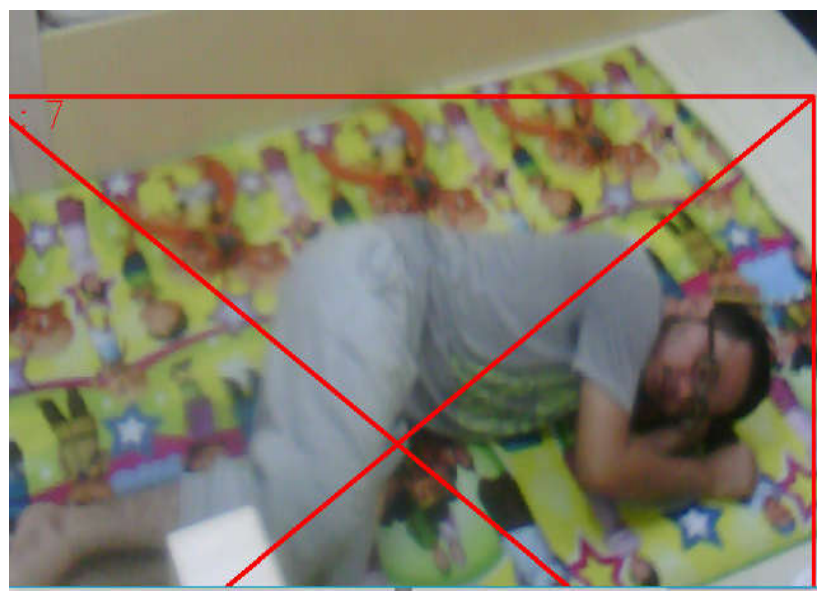

Figure 7 - Fall Detection Test

Figure 4 - Background Subtraction Method to detect Movement 
Table 3 - Testing Design

\begin{tabular}{|c|c|c|c|}
\hline Test & Purpose & Environment & Result \\
\hline $\begin{array}{l}\text { Movement } \\
\text { detection } \\
\text { camera }\end{array}$ & $\begin{array}{l}\text { To test the integration between } \\
\text { Raspberry } \mathrm{Pi} \text { and Webcam to } \\
\text { detect motion. }\end{array}$ & $\begin{array}{l}\text { A person needs to create a } \\
\text { motion/movement within } \\
\text { the camera's view. }\end{array}$ & $\begin{array}{l}\text { Figure } 5,6 \\
\text { Green box }\end{array}$ \\
\hline $\begin{array}{l}\text { Fall detection by } \\
\text { camera }\end{array}$ & $\begin{array}{l}\text { To test the integration between } \\
\text { Raspberry } \mathrm{Pi} \text { and Webcam to } \\
\text { detect motion. }\end{array}$ & $\begin{array}{l}\text { A person needs to pretend } \\
\text { to fall and stay in static } \\
\text { posture for around } 10 \\
\text { seconds. }\end{array}$ & $\begin{array}{l}\text { Figure } 7 \\
\text { Red box }\end{array}$ \\
\hline Notification Test & $\begin{array}{l}\text { To test the integration between } \\
\text { Raspberry } \mathrm{Pi} \text { and Telegram } \\
\text { Application to receive and send } \\
\text { notification. }\end{array}$ & $\begin{array}{l}\text { A person needs to pretend } \\
\text { to fall and when the } \\
\text { program detects a fall, the } \\
\text { system will send the } \\
\text { notification to Telegram. }\end{array}$ & Figure 8 \\
\hline Server Test & $\begin{array}{l}\text { To test this prototype, the recorded } \\
\text { file is saved in servers and can be } \\
\text { accessed by the owner. }\end{array}$ & $\begin{array}{l}\text { The recorded video will be } \\
\text { saved in server/cloud. }\end{array}$ & \\
\hline
\end{tabular}

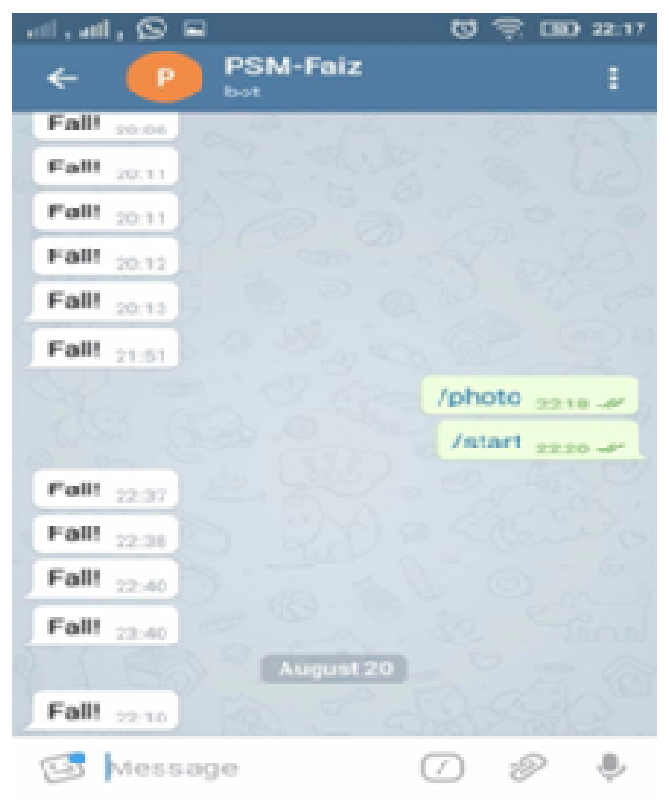

Figure 8 - Notification Received by User

\section{CONCLUSION}

In this paper, the development of a low-cost monitoring system for elderly persons with embedded fall detection module has been discussed. The motivation of the proposed system is to ensure safety of the elderly that have to live alone at home during day hours, where most of the young family members are away from home for working. Our developed system is equipped with a low cost single board computer with embedded simple web camera to enable 24 hours of home monitoring. The camera also can detect fall incidents among the elderly, without using additional sensors. Since incident notification is sent to the family members that might be away from home using IoT technology, adequate action can be taken to handle any incident and undesired cases such as serious injuries and death could be avoided. Furthermore, the recorded and saved in the cloud/server can be used in any event of forensic process in the future. Each proposed functions also have been tested to ensure the system can work properly. For future work, we would like to expand the investigation to handle privacy and security issue implementing the proposed system.

\section{ACKNOWLEDGMENTS}

The authors are fully acknowledging the Center of Advanced Computing (C-ACT) and Universiti Teknikal Malaysia Melaka (UTeM) for the funding support.

\section{REFERENCES}

[1] D. B. Kaplan, The Elderly Living Alone, MSD Manual, Professional version, 2016. [Online]. Available: https://www.msdmanuals.com/ professional/geriatrics/social-issues-in-theelderly/the-elderly-living-alone

[2] National Human Rights Society. Malaysia needs laws to protect rights of elderly, 2017. [Online]. Available: http://hakam.org.my/wp/ 2017/06/02/malaysia-needs-laws-to-protectrights-of-elderly/

[3] The Star Online, More women working now, 2016. [Online] Available: https://www.thestar. com.my/news/nation/2016/06/28/more-womenworking-now-female-participation-up-by$750000 /$ 
[4] Y. Cheng, C. Jiang, and J. Shi, "A Fall detection system based on SensorTag and Windows 10 IoT core," International Conference on Mechanical Science and Engineering, Qingdao, 2015, pp. 1-7.

[5] V. S. Borle and S. N. Kulkarni, "An enhanced fall detection system for elderly person and monitoring using GSM and GPS," International Journal of Advanced Research in Computer Science, vol. 7, no. 3, pp. 143-146, 2016.

[6] J. S. Madhubala and A. Umamakeswari, "A vision based fall detection system for elderly people," Indian Journal of Science and Technology, vol. 8, no. S9, pp. 167-175, 2015.

[7] M. Kreković, P. Čerić, T. Dominko, M. Ilijaš, K. Ivančić, V. Skolan I and J. Šarlija, "A method for real-time detection of human fall from video," IEEE MIPRO 2012, May 21-25, 2012, Opatija, Croatia.

[8] D. Aishwarya and J. A. Renjith, "Enhanced home security using IOT and Raspberry Pi," International Research Journal of Engineering and Technology, vol. 4, no. 4, pp. 3155-3158, April 2017.

[9] S. V. Gawande, P. R. Deshmukh, "Raspberry Pi Technology," International Journal of Advanced Research in Computer Science and Software Engineering, vol. 5, no. 4, pp. 37-40, April 2015.

[10] H. Zhang, J. Li and B. Wen, "Connecting intelligent things in smart hospitals using NBIoT," IEEE Internet of Thing Journal, vol. 5, no. 3, pp. 1550-1560, June 2018.

[11] J. Liu, Y. Chen, Y. Wang, X. Chen and J. Yang, "Monitoring vital signs and postures during sleep using WiFi signals," IEEE Internet of Thing Journal, vol. 5, no. 3, pp. 2071-2084, June 2018.

[12] B. Großwindhager, A. Rupp, M. Tappler, M. Tranninger, S. Weiser, B. Aichernig, C. Boano, M. Horn, G. Kubin, S. Mangard, M. Steinberger, \& K. Römer, "Dependable internet of things for networked cars," International Journal of Computing, vol. 16, issue 4, pp. 226-237, 2017.

[13] L. P. Koon, and M. Mahinderjit Singh, "iHOME: an ambient intelligence mobile crowdsensing smart home system," Proceedings of the Knowledge Management International Conference KMICe'2016, 29-30 August 2016, pp. 104-109.

[14] N. Harum, N. A. M. Yusof, and N. A. Zakaria, "The development of personal portable wireless range extender for IEEE 802.11," in Proceedings of the CSSR 3rd International
Conference on Science \& Social Research, 2016.

[15] C. Perera, A. Zaslavsky, P. Christen, and D. Georgakopoulos, "Context aware computing for the Internet of Things," IEEE Commun. Surv. Tutorials, vol. 16, no. 1, pp. 414-454, 2014.

[16] N. A. Zaini, N. Zaini, M. F. A. Latip, and N. Hamzah, "Remote monitoring system based on a Wi-Fi controlled car using Raspberry Pi," Proceedings of the IEEE Conference on Systems, Process and Control (ICSPC), 2016, pp. 224-229.

[17] M. Rouse, Definition CCTV, 2016. [Online]. Available: FTP: http://whatis.techtarget.com/ definition/CCTV-closed circuit-television.

[18] N. Yang, "Motion sensor and camera placement design for in-home wireless video monitoring systems," Proceedings of the IEEE Globecom, 2011, pp. 1-5.

[19] C. Severence, E. Upton, "Raspberry Pi," IEEE Computer Magazine, vol. 46, issue 10, pp. 1416, 2013.

[20] W. F. Abaya, J. Bassa, and M. Sy, "Low cost smart security camera with night vision capability using Raspberry Pi and OpenCV," Proceedings of the IEEE International Conference on Humanoid, Nanotechnology, Information Technology, Communication and Control, Environment and Management (HNICEM), 12-16 November 2014, Palawan, Philippines, pp. 1-6.

[21] S. Singh, P. Anap, Y. Bhaigade, and J.P. Chavan, "IP camera video surveillance using Raspberry Pi," International Journal of Advanced Research in Computer and Communication Engineering, vol. 4, no. 2, pp. 326-328, February 2015.

[22] F. P. Tso, D. R. White, S. Jouet, J. Singer, D. P. Pezaros, "The Glasgow Raspberry Pi Cloud: a scale model for cloud computing infrastructure," Proceedings of the IEEE 33rd International Conference on Distributed Computing Systems Workshops, 2013, pp. 108112.

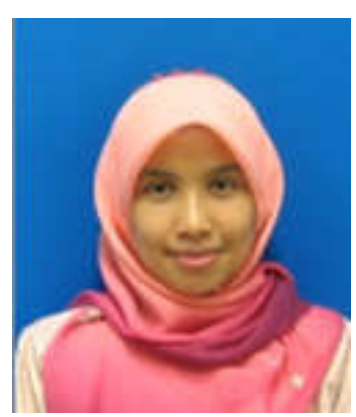

Norharyati Harum holds her Bachelor in Engineering (2003), MSc. in Engineering (2005) and PhD in Engineering (2012) from Keio University, Japan. She has experience working in R\&D Department of Next Generation Mobile Communication at Panasonic Japan (2005- 
2009). ). She is currently a senior lecturer at Faculty of Information and Communication Technology, UTeM. Her interests in research area are Internet of Things, Wireless Sensor Network, Next Generation Mobile Communication and Signal Processing. She is an accomplished inventor, holding patents to radio access technology, copyrights of products using loT devices

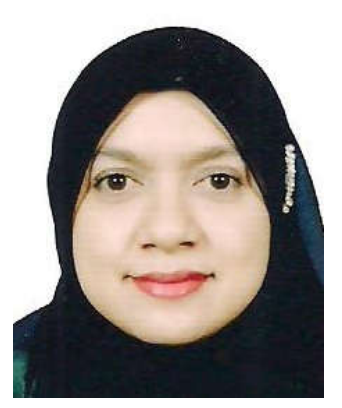

Lecturer in the Department of Computer System and Communication at Universiti Teknikal Malaysia Melaka. She is a member of the Information Security, Digital Forensic, and Computer Networking research group. Her research interests include system and networking, network security and IoT related technology.

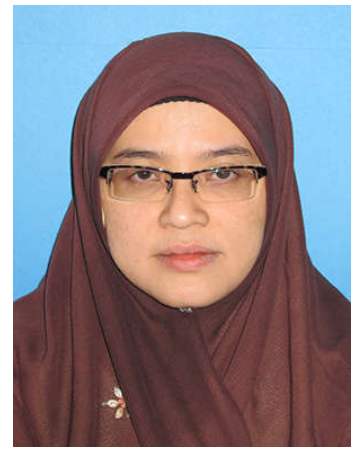

Aslinda Hassan received her PhD degree in Electrical Engineering, from Memorial University of Newfoundland, St. John's, NL, Canada in 2014. She received M.Sc. degree in Computer Science, from Universiti Teknologi Malaysia (UTM) and B.SC. degree in Business Administration with honors, from University of Pittsburgh, Pittsburgh, PA, USA in 2001 and 1999, respectively. In 2004, she joined Universiti Teknikal Malaysia Melaka, where she is currently a Senior Lecturer at Faculty of Information and Communication Technology. Her research interests include in vehicular ad hoc network, vehicular communication, wireless ad-hoc network, wireless sensor network, wireless communication, ad hoc routing protocols, cyber-physical systems (CPS), Internet of Things (IoT), network performance modelling and analysis as well as network programming interfaces.
Utara Malaysia, Master of Computer Science from Universiti Teknologi Malaysia and PhD in Computer Science from Lancaster University, UK. She is currently a Senior
Wahidah Md Shah holds her Bachelor of Information Technology from Universiti

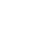

\begin{abstract}
Zaheera Zainal Abidin Information Technology from Australia, 2002. She joined Regional Center as a Project Analyst in 2000-2001. She Quantitative Sciences (2004),
\end{abstract} MSc. in Computer Networking (2008) and PhD in of Computer and Mathematical Sciences, Universiti Teknologi MARA, Shah Alam, Selangor. She served and Universiti Teknikal Malaysia Melaka (2009 present). Her research interests include network

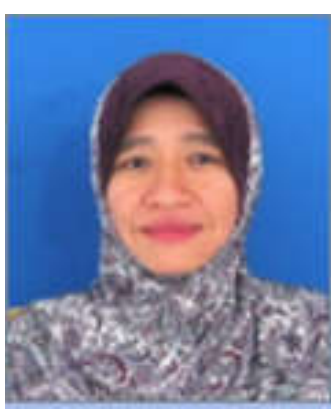

